\title{
Parental opinions of their child's experience in the legal process: an interpretative analysis
}

Christina Back, Per A. Gustafsson and Carina Berterö

\section{Linköping University Post Print}

\section{Tweet}

N.B.: When citing this work, cite the original article.

This is an electronic version of an article published in:

Christina Back, Per A. Gustafsson and Carina Berterö, Parental opinions of their child's experience in the legal process: an interpretative analysis, 2014, Journal of Child Sexual Abuse, (23), 3, 290-303.

http://dx.doi.org/10.1080/10538712.2014.888117

Copyright: Taylor \& Francis (Routledge): STM, Behavioural Science and Public Health Titles http://www.routledge.com/

Postprint available at: Linköping University Electronic Press

http://urn.kb.se/resolve?urn=urn:nbn:se:liu:diva-106914 


\title{
Parents' opinions - view of their child's experiences in the legal process:
}

\section{An interpretative analysis of parents`opinions}

\author{
Christina Back \\ Faculty of Health Sciences, Linköping University, Sweden \\ Per A. Gustafsson \\ Faculty of Health Sciences, Linköping University, Sweden \\ Carina Berterö \\ Faculty of Health Sciences, Linköping University, Sweden
}

The aim of this study was to demonstrate how parents of children, who are victims of sexual assault, experience the legal process, seen from the child's, as well as the parents' perspective. Nine parents, identified in the records of three public prosecution offices in three cities in Sweden, were interviewed. The parents described feelings of shame and guilt over what their children had experienced. They felt stigmatized and had difficulty fulfilling their parental role; perceived a lack of information and support from the professionals involved; experienced a sense of withdrawal from their role as parents, though they felt the professionals who worked with their children were helpful and influential.

Keywords: child sexual abuse, legal process, parents' opinions, interpretative analysis Correspondence: Christina Back, Division of Child \& Adolescent Psychiatry, Department of Clinical and Experimental Medicine (IKE), Faculty of Health Sciences, Linköping University, Sweden.

Email: $\underline{\text { Christina.Back@liu.s }}$ 
Children who have suffered a crime such as a sexual assault face several challenges. Though Child Sexual Abuse (CSA) does not leave visible effects as often as physical abuse, it does leave lasting psychological damage (Finkelhor \& Browne, 1985). Subsequently, when children have been victims of crime it is of great importance that they are supported in an adequate way while participating in the legal process. Some countries have developed special Court Education for Young Witnesses and also specialised Children's Advocacy Centres. The aim of these centres is to increase multidisciplinary coordination in sexual abuse investigations, provide an independent, child-friendly environment for forensic interviews, increase training for interviewers and increase children's access to medical and therapeutic services.

Research suggests that experiencing prolonged criminal court proceedings is a stressor for CSA victims and can be detrimental to a child victim's mental health (Prior, Glaser, \& Lynch, 1997). We know that the child's own story should be, and is, central to any set of legal proceedings, but we also know that children find it difficult to talk about sexual abuse. The main reason for this difficulty is probably that talking about the abuse arouses strong emotions that can be difficult to deal with (Leander, Christianson \& Granhag, 2008; Svedin \& Back, 2003).

Child advocates, policy makers, prosecutors, judges, and other legal professionals need to work together to develop ways to increase the collaboration of all parties involved in CSA cases while at the same time trying to work toward producing the fairest possible legal outcome (Walsh, Lippert, Cross, Maurice \& Davison, 2008). Previous studies show that nonoffending parents have the feeling of being treated negatively by professionals when it has been revealed their children have been sexually abused (Plummer \& Eastin, 2007). It appears, in many cases, that protecting the child from family makes it especially difficult to investigate the alleged crime, and thus, very few convictions result. In most countries, there is 
a protective legislation which means that if the social authorities suspect that a child is being mistreated and that the parent is unable to care for their children, the social services can take care of the child regardless of the parent's wishes and may place the child in another home so that the child's needs are better fulfilled.

Many studies have shown that parental support is important for children who have experienced CSA (Coulborn Faller \& Palusci, 2007). Several studies have provided strong evidence that both mothers and fathers also frequently experience distress. One of the most important and consistent findings in the literature is that support/protection for nonoffending caregivers is a factor leading to better emotional and behavioral adjustment of sexually abused children (Elliott \& Carnes, 2001). However, it is common that parents have hesitant feelings, beliefs, and may even display ambivalent behavior toward their children after the children have disclosed being subjected to sexual abuse. Traditionally, it has been assumed that ambivalent non-offending parents are not adequately supportive of their children after disclosure, but Bolen and Lamb (2007) have hypothesized that a strong desire for the parents to provide support may coexist with feelings of ambivalence about the specific abuse that a child has experienced. Parental distress has been shown to be significantly associated with children's post-abuse adjustment (Cohen \& Mannorino, 2006).

Child victims have special needs in the criminal justice procedure but their needs are often neglected. These needs are connected to special problems, about which there is a substantial lack of knowledge. Plummer and Eastin (2007) suggest it was helpful when professionals assisted mothers with information and advice. Professionals cognizant of how the event of disclosure may undermine mother's confidence instead they should assist mothers in rebuilding their parental self-esteem. In this study the mothers felt tired and overwhelmed. This exhaustion both reduced energy they had for normal parent/child activities and made the child the central focus of their concerns (Plummer \& Eastin, 2007). 
The level of family support has been identified as one of the most important predictors of the degree to which the child can adjust following the disclosure of CSA (Debra\& Hecht, 2000). The purpose of this study was to describe how parents perceive the judicial process based on their own and their children's reactions when their child is suspected of having been sexually abused. More precisely it was of interest to better understand how they, the parents, experience the process on their own, in particular when they come into contact with officials from other key agencies. The study is focused on the non-offending parents' perspective of their own experiences after their child's disclosure of sexual abuse is made.

\section{Method}

The aim of Interpretative Phenomenological Analysis (IPA) is to explore the informantsinformants' views of the world and to closely adopt an "insider perspective," recognizing that the research exercise is a dynamic process (Smith, 1996; Smith, Flowers \& Larkin, 2009). IPA draws on the traditions of phenomenology, hermeneutics and symbolic interactionism in attempting to understand how people make sense of their experiences. One important theoretical touchstone for IPA is the phenomenology that originated with Husserl's attempts to construct a philosophical science of consciousness. A second important theoretical current for IPA is recognition that hermeneutics is a theory of interpretation (Smith, 1996). A third significant influence is symbolic interactionism, a concept that emerged in the 1930s as an explicit rejection of the positivist paradigm that was then beginning to take hold in the social sciences (Blumer, 1997).

For symbolic interactionism, the meanings that individuals ascribe to events are of central concern, but those meanings can only be obtained through a process of social engagement and a process of interpretation (Blumer, 1997). In general, data collection and sampling in IPA are based on purposive sampling, where informants' accounts are selected 
based on their relevance to the research questions. A fairly homogeneous sample is needed; a sample for which the research question will be meaningful (Smith, et al., 2009).

In phenomenological studies the groups commonly range in size from 5 to 25 informants (Kvale, 1996). The number of informants in IPA studies is usually quite small since the aim is to reveal something of the experience of each person in a set of individuals, based on very careful examination of each individual. Our main focus was to learn by very detailed examination how each individual made sense of a major transition (Smith, et al. 2009).

\section{Participants}

The participants in this study were identified in the records of three public prosecutions offices in three cities in Sweden. Fifty children were asked by letter to participate in interviews, and ten children and nine parents responded positively. One participant was a foster parent with whom the child had been living with a long time. Another had two daughters who had been part of the legal process, and the account of her case refers to both daughters. All the parents interviewed were non-offending parents and in most cases these parents had no idea about the sexual abuse; however, in a few cases the parent had had suspicions. The perpetrator was a father or stepfather in four cases, an acquaintance in four cases and in the remaining two cases the perpetrator was a stranger. The actual legal proceedings took place between 2000 and 2004. Further, the names of the children are fictitious. Please see table 1 for more information.

Table1. Informants

Interviewed

Age of the child

Perpetrator

\begin{tabular}{|l|l|l|}
\hline Mother to Maria & 12 & Stepfather \\
\hline Mother to Linda & 15 & Friend's father \\
\hline
\end{tabular}




\begin{tabular}{|l|l|l|}
\hline Foster mother to Sara & 13 & Father \\
\hline Father to Britta & 15 & Stranger \\
\hline Mother to Cecilia & 12 & Friend to family \\
\hline Mother to Hannes & 12 & Friend's father \\
\hline Mother to Karolin & 14 & Neigbour \\
\hline Mother to Viktoria & 15 & Stepfather \\
Madde & 10 & Father \\
\hline
\end{tabular}

\section{Procedure}

Participants were interviewed by using a semi-structured interview following guidelines set out by Patton (2002). The participants were asked to talk as extensively as possible about what they thought the child had experienced in the legal proceedings, and what they themselves had experienced in their role as parents. The questions were openended, and informants used their own words and were encouraged to express their own personal views of the legal process and their specific experiences. Participants were encouraged to talk in detail about the particular concerns they had, and they were asked to further explain more about important individual topics that arose. Examples of questions were, "Tell me about the child's meeting with the professionals" and "Tell me about your experiences of participating as a parent of a child in the legal process."

All the interviews took place at the child and adolescent psychiatric clinic. Each interview lasted for one to two hours and was audio taped with the consent of each participant. These tapes were later transcribed verbatim. The study was approved by the ethical committee of the Faculty of Health Sciences, Linköping University (Dno 03-437). 


\begin{abstract}
Analysis
The first stage of the analysis was to read and reread the transcription of each interview in order to identify themes that appeared to characterize each section of the text. The second stage of analysis required the researcher to label the themes that were identified. These themes were named and recorded in the right margin. The third stage involved an attempt to create a structure for the analysis. The themes identified in stage two were reflected upon and an effort was made to see them in relation to one another. Some of the themes formed natural clusters of concepts that share meanings or references. The fourth stage of analysis involved the production of a summary of the structured themes, together with quotations, that illustrate each theme (Smith, et al., 2009). A master list of themes was produced for each individual case, and at this stage, some themes were removed because they were not supported by the data (Smith, et al., 2009). This process was repeated for each case, and patterns were established cross-case and documented in a master list of themes for the group. Irrespective of the approach used, integration should generate a list of master themes that captures the quality of the participant's shared experience of the phenomenon under investigation, and which, therefore, also tells us something about the essence of the phenomenon itself.
\end{abstract}

The three superordinate themes that emerged were: (1) stigmatization, (2) need of support in the parental role, and (3) transforming consequences to reality. The list of master themes should include the labels of superordinate themes and their constituent themes, together with identifiers that indicate which of the informants invoked them and where they did so. Finally, the superordinate themes were transformed into a narrative account, where the themes were outlined, exemplified and illustrated with verbatim extracts from the informants (Smith \& Osborn, 2003). 
As a researcher, one is drawing on one's interpretative resources to make sense of what the person is saying, but at the same time, one is constantly checking one's own sense making against what the person actually said (Smith \& Osborn, 2003). In IPA, analysis examines both semantic content and language use; the principles for assessing the quality of qualitative research are: sensitivity to context, commitment and rigour, transparency and coherence, and finally, the impact and importance of the qualitative research (Smith, et al., 2009).

\section{Results}

Three superordinate themes emerged from an analysis of the data from the nine participants: 1) stigmatization, 2) need of support in the parental role, and 3) transforming consequences to reality.

\section{Stigmatization}

The parents in the study were all non-offenders, but in spite of this, they reported experiencing feelings of shame and of blaming themselves. Some of the parents have had suspicions that the children have been sexually abused without doing anything about it. It may have contributed to these feelings. They focused on how incompetent and inadequate they had felt and they made clear that they had developed a negative self-image of themselves and that they had feelings of withdrawal. The participants described feelings of helplessness. They found themselves alienated and were having trouble understanding how the abuse could possibly have happened. They also had concerns about if neighbors and schoolmates to the children knew what had happened. Almost all participants had concerns about whether they would move to another city or not.

I felt completely left out and we could not meet...because she went to another home, and then I did not know what was had been said...because she said to me 
that I would not get to meet her. Now I can think; 'But why didn't I say something to her,' but I was not strong. (Maria's mother).

Informants also said that it seemed as if agency officials felt that they did not count at all in making future plans for the child.

There was an awful lot that was planned for Viktoria without my being consulted. It was made clear to me that the children were not to be at home ...but... I did not want to give them up... so finally it was decided that I would be able to go with them. (Viktoria's mother).

Victoria's mother wanted to be granted sole custody when her husband was serving his sentence, and she had submitted all the correct documentation to the Social Welfare Office, regarding the sexual abuse her husband was convicted. Victoria's mother felt that she had been ignored and, in some way, treated as an offender, in the same way as the father.

When he was going into prison I applied for sole custody. I had sent copies to the judge, and she had not even read them. So there we are, sitting together, and Sten refuses to grant me sole custody, and then she asks me if I might allow my daughter to go with him to the mountains, and that was the first time. I felt so humiliated. (Viktoria's mother).

There were a number of parents who said that Social Services had, in effect, taken over the role of parent and prevented the parents from taking part in the everyday care of their children. Although the children were not taken into custody by Social Services, they made some decisions over the parent's head.

\section{Need of support in the parental role}

As a result of the stigmatization of the parents, they experienced feelings of withdrawal and exclusion from being informed about the situation of their children in the legal process. They began to have doubts about their importance to the child during the 
proceedings. The parents presented a picture indicating that from some point in the process an experience developed that only the professionals were of any importance in working with the children. Informants did not provide a picture of having been asked explicitly if they wanted some kind of support or psychological consultation for their children or for themselves. The parents who had received support from or treatment by child psychiatric services (CPS) for their children had all been satisfied with these contributions. The contacts with child psychiatry also provided further confirmation that CSA had occurred.

But everything went well and thanks to (CPS) Britta gained confidence in them. (Britta's mother).

Yes CPS has been good for her and she has been able to go there and talk. (Sara's foster mother).

Afterwards both Hannes and I were really sad and we got to go directly to CPS to talk, and I think that helped Hannes a lot and he got to tell the story again in his own words, and I think that was great to get support from them. (Hannes' mother).

Linda's and Karoline's mothers show a big disappointment when a contact with CPS is refused:

We were promised a contact at CPS but nothing happened and she still suffers from severe anxiety, and she can have anxiety attacks when she thinks she is going to suffocate so she has to tear off her clothes and go out to get fresh air and such.Karoline's mother says:

I requested help from CPS right away, I think during the same week that the abuse was revealed, but there was no reason for her to go there.

'Here at CPS there isn't anything that indicates that she should come here' they said and (they) looked down in their papers... all these ladies. 
It is shown that parents experience a positive and supportive way their children are treated with support and kindness given by various professionals who worked with their children. However, it is also shown that there is a possibility that parents can feel excluded in this process if the importance of the parental role is reduced or challenged in some other way. When it comes to the non-offending parent's role in the legal process, there were several parents who said that they had not received any information about that. There was for example no explanation about why they should not be included in the process during the police interrogation.

When we first filed a report with the police, we were with our child, but then when there was going to be a police interview that was to be videotaped, I was not allowed to be present, and I did not like that; he is only a child. (Hannes' mother).

In a similar way, Linda's and Karoline's mothers described the experience of their daughters' police interrogation.

Linda got to talk with someone and she was alone. She might have needed a female police officer who could sit next to her; she was really alone. I do not know what was said in the interview, and I have not seen a summary or anything at all. (Linda's mother).

Yes, she had to go in and they carried out the standard filming then, and I sat outside in the waiting room and I did not get to say anything about anything. I was just out in the waiting room. (Karoline's mother). 


\section{Transforming consequences to reality}

In some cases, the legal process had continued over several years with the result that both parents and children felt psychologically unwell. The long period was partly due to the long wait for a court hearing. The parents believed that at some point the children wanted to simply put a stop to the process, leave both the offense they had suffered and the legal process behind them. They wanted to move on in life. The parents and children both felt that finally putting an end to the process was important for the restoration of their mental health.

We really did not know how we should proceed, but then I began to make phone calls because time had passed and I did not get any answers from anyone. Months passed and I just had to wait...I mean she could not begin to process all she had been through until a trial had been held. (Linda's mother).

It took 2-3 years before everything was finished. He said, 'Mom, I cannot manage,' and I understood him because the trial was there all of the time in the back of his mind. Then I think that even the kids in school passed judgment on him and looked at him in a different way and he did not have so many friends, but he was careful because he did not trust people very much and I think it was taxing for Hannes, and then it got that way for me too as parent. (Hannes' mother).

It was a really long process, it really moved slowly so you are thinking all the time when are we going to get into court? It might be in a week, a month and in some way you are involved in the thing constantly. No, you cannot go up on some kind of plateau where you can leave everything behind you, but I really wonder why it has to take so long. It is difficult. (Viktoria's mother). 
When the hearing in court was in progress most informants experience that in positive terms and they also report having positive experiences of their children's physical participation in the court hearings and of appearing alone in a police interrogation video. As Lindas'mother stated:

I think it is important that they take part in the trial. Yes, she was really relieved afterwards and satisfied with herself.

Viktoria's mother was impressed by the strength her daughter showed during the trial. This suggests that Viktoria may well be a subject who felt fully involved in the judicial proceedings. With good support and preparation for the trial, therapeutic intervention can also help to accelerate the restoration of mental health. Viktoria was aware of the consequences that the sexual abuse had on her, and she felt comfortable with actually getting ready to take part in the trial and to describe what had happened.

In contrast with the ability of her daughter to move on, her mother was still experiencing the stigma and the associated feelings of shame and guilt.

But Viktoria was completely calm and she sat there throughout, and even the day that it had to do with Madde (her little sister), she sat there in front in the circle. We had not talked so much about it; I just thought she was so unbelievably strong, she was so fact-oriented - bang, bang, bang throughout really.

\section{Discussion}

Parents have an overall formal responsibility for their children's care and protection. This is a strong societal norm that parents usually strive to follow. When children are sexually abused the question about parents' responsibility becomes important. In fact, even if the parent could not possibly, in any way, have prevented the child from being abused the question still seems to come up. It has been previously reported that parents of children who 
have been subjected to sexual violence seem to experience a sense of failure in parenting, and the participants in this study also reported such a sense of failure.

Besides parents own tendency to blame themselves for things they possible not could have prevented, people in different social agencies such as police, social workers, lawyers and prosecutors also more or less openly put blame on the parent. Therefore, parents can get a feeling that the society may look down on them. This process of stigmatization has previously been reported, not only to apply to children who have been sexually abused, but also the parent or parents of these children may be perceived as stigmatized (Finkelhor \& Browne, 1985; Coffey, et al., 1996).

Our findings confirm that the participants often feel both shame and guilt, similar to the findings of Plummer and Eastin (2007). In that study, it was found that when professionals assisted them with information and advice, this was helpful. Our study also supports that professionals investigating and treating child sexual abuse should be cognizant of how the event of disclosure may undermine parents confidence and assist them in rebuilding their parental self-esteem. Support from the parents to the child seems to be an important part of the child's rehabilitation process, as demonstrated by the findings of Deblinger, Stauffer, and Steer (2001).

Our findings also confirm what other researchers report: that shame and guilt become ingredients of the stigma (Feiring, Taska, \& Lewis, 1996). In that study it became clear that stigma affects not only the children who have experienced sexual abuse but their families as well - a guilt by association effect. In spite of the importance of "stigma by association," this phenomenon has received comparatively little attention (Östman \& Kjellin, L., 2002). Other studies have confirmed that the process of stigma by association affects other family members when one member has been sexually abused (Lefley, 1987; Byrne, 2001; Struening et. al, 2001). 
Our study revealed that the parents wished to have contact with a treatment professional, and those who received such a contact felt confirmed and saw this as a further strengthening of the child as a victim of crime. Those who did not receive such contact perceived that they and their children were not taken seriously. There was no assessment of whether the children needed treatment or not. This weakness in the process is linked to estimates of whether the crime was a traumatic experience or not and to the fact that different children react differently to a particular traumatic experience.

Results of a study by Feiring \& Simon (2009) indicate that sexually abused youth who experience persistent abuse-specific shame and self-blame may later encounter difficulties in sexual functioning. Early interventions that target the youth's cognitive and emotional processing of the abuse may not only alleviate concurrent distress, but may also help to prevent subsequent sexual problems. Support from the parents to the child is an important part of the child's rehabilitation process, as demonstrated by the findings of Deblinger, Lori, and Stauffer (2001). However, the study also shows that children and parents can be in various stages of their rehabilitation. Vitoria's case demonstrates this when Viktoria herself felt well prepared to participate in the court while her mother still felt guilt and stigmatized.

The legal process can have a negative effect on the mental health of both the children and the parents, and the longer the legal process goes on, the greater the impact. It is only when the legal process is completed that parents and children can stop thinking about the case and move on in life. Additionally, children's needs for support and basic caretaking could be compromised if caregivers are upset and confused by the investigation process. As with children, parental satisfaction with investigations appears to increase with the perceived supportiveness of the involved professionals and when they have good access to information about what is happening with the investigation (Jones, Cross, Walsh, \& Simone, 2007). 
The analysis in this study highlights the degree to which the parents felt that the children's participation in the courtroom contributed to a positive process. The parents gave examples of positive responses the children received from members of the legal profession. Where this happened, it meant that the child could feel a sense of redress, and this was felt most strongly in cases where there was a conviction. Research has shown that whereas some children are negatively affected by their experience with legal proceedings, other children say that testifying had a positive connotation for them and they felt a certain empowerment from taking part in the investigation (Goodman et al, 1992; Ghetti et al, 2002; Back, Gustafsson, Larsson \& Berterö, 2011). It has also emerged in this study that the parents felt "left out," and that they felt as though social services had completely taken over their parental role. Some said that they received little or no information from either social services or child psychiatry representatives, but others who had received information, said they had been satisfied.

The study has shown that there is a need for more organized interventions to support the normal functional parenting through the legal process and support the relation between the child and non-offending parent. It is shown that there is a need to give information about the legal process such as realistic timelines and when interrogations and the trial are going to take place. It is also demonstrated that short trials are preferred. These factors are seen as important facilitating the opportunities for the family to recover, plan their time and look forward.

\section{Limitations}

A potential limitation of this study should be noted. The IPA method does have a limitation that arises from our choosing to use the spoken word to describe the world and the experiences. In the language that the parents choose to describe a particular experience and in 
the language we researchers then choose, we are together always constructing a particular version of that experience.

\section{References}

Back, C., Gustafsson, P.A., Larsson, I., \& Berterö, C. (2011). Managing the legal proceedings: An interpretative phenomenological analysis of sexually abused children's experience with the legal process. Child Abuse \& Neglect, 35, 50-57 doi:10.1016/j.chiabu.2010.08.004

Bolen, R.M., \& Lamb, J. L. (2007). Can nonoffending Mothers of Sexually Abused Children Be Both Ambivalent and Supportive? Child Maltreatment, 191-197 Doi: $10.1177 / 1077559507300132$.

Byrne, P. (2001). Psychiatric stigma. British Journal of Psychiatry, 178, 281-284

Coffey, P.,Leitenberg, H., Henning, K., Turner, \& Bennett, R.T. (1996a). Mediators of the long-term impact of child sexual abuse: perceived stigma, betrayal, powerlessness, and self-blame. Child Abuse \& Neglect, 20, 447-455. 
Cohen, J., Mannorino, A., \& Deblinger, E. (2006). Treating Trauma and Traumatic Grief in Children and Adolescents. The Guilford Press, New York.

Coulborn Faller, K. \& Palusci, V.J. (2007). Children's advocacy centers: Do they lead to positive case outcomes? Child Abuse \& Neglect, 31, 1021-1029 doi:10.1016/j.chiabu.2007.09.001.

Deblinger, E., Stauffer, L.B., \& Steer, R. A. (2001). Comparative Efficacies of Supportive and Cognitive Behavioural Group Therapies for Young Children Who have Sexually Abused and their Nonoffending Mothers. Child Maltreatment, 6, 332343 doi:10.1177/1077559501006004006

Elliott, A. \& Carnes, C.N., (2001) Reactions of nonoffending parents to the sexual abuse of their child: A review of the literature. Child Maltreatment, 6,314-331 doi:10.1177/1077559501006004005Feiring. C., Simon V.A. (2009). Childhood

Sexual Abuse, Stigmatization, Internalizing

Symptoms and the Development of Sexual Difficulties and Dating Aggression. Journal of Consulting and Clinical Psychology,77, 127-137 doi:10.1037/a 0013475 Finkelhor, D., \& Browne, A. (1985). The traumatic impact of child sexual abuse: a conceptualisation. American Journal of Orthopsychiatry, 55, 530-541.

Feiring. C., Taska, 1.s., \& Lewis, M. (1996). A process model for understanding adaption to sexual abuse: The role of shame in defining stigmatisation. Child Abuse \& Neglect, 20, 767-782. 
Ghetti, S., Alexander, K., W., \& Goodman, G.S. (2002). Legal involvement in child sexual abuse cases Consequences and interventions. International Journal of Law and Psychiatry, 25, 235-251 doi:10.1016/30160-2527(02)00104-8.

Goodman, G.S., Taub, E.P., Jones, D.P., England, P., Port, L., K., Rudy, L., \& Prado, L. (1992). Testifying in criminal court: Emotional effects on child sexual assault victims. Monographs of the Society for Research on Child Development, 57 (5, Serial No.299).

Hecht, D., B. (2000). The role of family support in child adjustment and response to treatment after sexual abuse. Dissertation Abstracts International: Section B: The Sciences and Engineering, 61, 2201.

Jones, L.M, Cross,T.P., Walsh,W.A., \& Simone,M. (2007). Do Children`s Advocacy Centers improve families'experiences of child sexual abuse investigations? Child Abuse \& Neglect, 31, 1069-1085 doi:10.1016/j.chiabu.2007.07.003.

Leander, L., Christianson, S.Å., \& Granhag, P.A. (2007). A Sexual Case Study Children’s Memories and Reports. Psychiatry, Psychology And Law, Vol.14, 120-129. doi:10.1375/pplt.14.1.120.

Lefley, H. (1987). Impact of mental illness in families of mental health professionals. 
Journal of Nervous and Mental Disease, 175, 613-619.

Patton, M.Q. (2002). Qualitative Research \&Evaluation Methods. Sage Publications.

Plummer, C.A. \& Eastin, J. (2007a). System problems in cases of child sexual abuse: The mothers’ perspectives. Journal of Interpersonal Violence, 22, 775-787.

Plummer, C.A. \& Eastin, J. (2007b). The effect of child sexual abuse

allegations/investigations on the mother/child relationship. Violence Against Women, 13: 1053-1071. doi:10.1177/1077801207305931.

Prior, V., Glaser, D., \& Lynch, M.A. (1997). Responding to child sexual abuse: The criminal justice system. Child Abuse Review, 6, 128-140 doi:10.1002/(SICI)10990852(199705)6:2<128.AID-CAR313>3.0.CO;2-6.

Smith, J. A., (2009) editor, Qualitative psychology: a practical guide to research methods. London: Sage.

Smith, J.A. (1996). Beyond the divide between cognition and discourse: Using interpretative phenomenological analysis in health psychology. Psychology \& Health, 11, 261271.

Smith, J.A., Flowers, P. \& Larkin, M. (2009) Interpretative Phenomenological Analysis. SAGE Publications.

Smith, J.A. \& Osborn, M. (2003): Interpretative phenomenological analysis, (pp. 52-80). 
Struening, E., Perlick, D., \& Link, B., (2001). The extent to which caregivers believe most people devalue consumers and their families. Psychiatric Services, 52, 1633-1638 doi:10.1176/appi.ps.52.12.1633.

Svedin, C., G., \& Back, C. (2003). Why the children tell? Save the children, Stockholm.

Walsh.W., Lippert.T., Cross.T., Maurice.D., \& Davison. K., (2008). How long to prosecute child sexual abuse for a community using a children's advocacy centres and two comparison communities? Child Maltreatment, 13, 3-13 doi:10.1177/1077559507307839 